\title{
INTERPERSONAL COGNITION AND METHODS OF ITS DEVELOPMENT IN FUTURE TEACHERS
}

\author{
Natalia A. Rozhdestvenskaya \\ Lomonosov Moscow State University \\ Moscow
}

\begin{abstract}
This article deals with researches on the cognitive component of interpersonal cognition and studies a possibility of improving it during teachers'education. Mistakes people make while estimating one another are analyzed on the basis of empirical researches. The author suggests a model describing main interpersonal cognition principles that is capable of minimizing such mistakes. The author describes the researches conducted under her supervision, in which the strategies based on the interpersonal cognition principles were studied. It has been shown that teachers using a model set of the interpersonal cognition principles are much better at estimating children's personality characteristics, than those who are unable to use them. The author also presents the method called The Development of the Strategies of Interpersonal Cognition, and considers forms and conditions of its usage in education of future teachers.
\end{abstract}

Keywords: interpersonal cognition, the strategies of interpersonal cognition, The Development of the Strategies of Interpersonal Cognition method, teachers' interpersonal cognition.

The effectiveness of interpersonal cognition ${ }^{1}$ as a kind of cognitive activity is mainly determined by adequacy and completeness of the knowledge of personality traits and by the quality of methods used to estimate them. Numerous researches dealing with the cognitive aspects of interpersonal cognition ${ }^{2}$ show that in everyday life people, as a rule, use certain notions of typical traits and behavioral reactions which psychologists call stereotypes, generalizations, implicit theories of personality, and social representations. Being instruments of cognition, they have

1 The terms: interpersonal cognition, interpersonal perception and interpersonal estimation are used as synonyms.

2 Many researchers believe that interpersonal cognition comprises a cognitive component, an affective component and a behavioral component. 
their own advantages and weak points. As far as their disadvantages are concerned, these notions distort human percept images, because they often rest upon an insufficient amount of essential features and comprise properties that bear no relation to phenomena reflected therein.

Besides, results of many studies within the framework of the wellknown theory of attribution demonstrate that images of people under consideration tend to be distorted, because people attribute non-existent reasons of behavior to one another. In particular, the foregoing occurs when an observer doesn't take into consideration specific circumstances that determine behavior of a studied person.

Excessively categorical judgements and so-called heuristics, or rules for estimating someone's personality traits, which are readily accessible and used in interpersonal cognition regardless of the fact that they are superficial and fail to include essential features of the specific aspects under investigation, have an adverse effect on interpersonal perception, too. A trend to judge a person by analogy leads to erroneous perception of his / her specific features. Mistakes in interpersonal estimation are grounded on a few isolated and insignificant observations concerning behavior of another individual. Misinterpretations of a human image can be explained by the fact that many people go through changes during their lives, but those who surround them don't notice these changes (Rozhdestvenskaya, 2004).

In spite of the fact that psychology has accumulated abundant empirical information about mistakes people make judging one another, unfortunately, there is no definite answer how we could resolve the issue of improving the thinking process directed to cognition of people. At the same time, we have arrived at the conclusion that some positive steps can be made in this direction, if we try to summarize the information about different mistakes of interpersonal cognition represented in various studies on the basis of the cognition principles defined by logic of the science. As a result we have singled out six principles of interpersonal cognition which allow to improve adequacy of interpersonal cognition (Pisarenko \& Rozhdestvenskaya, 1998; Rozhdestvenskaya, 2004). To understand a person better, one should:

1) estimate him / her comprehensively, it means according to the main qualities characterizing an orientation, contents, process and effectiveness of a person's activities. These qualities are: world view, intelligence, erudition, will, emotions, character and aptitudes; 
2) apply relevant and essential criteria for estimating such traits;

3) analyze both internal and external factors influencing a person (personality traits, emotional and functional states, health, other people, circumstances and conditions of life);

4) consider main biography events of an individual and prospects of his / her development;

5) use probability judgments about a person;

6) verify judgements within the sphere of practical activities typical for a person.

Later on, a group of psychologists supervised by the author have carried out two empirical researches. One of them is devoted to teachers' interpersonal cognition and the other studies the conditions of interpersonal cognition development in students of a teacher's training institute and parents (Grachikova, 2002; Melnikova, 2007; Razumova, 2004; Rozhdestvenskaya, 2004).

In her research Grachikova compared two types of teachers (Grachikova, 2002). Some teachers estimated children spontaneously on the basis of the principles of interpersonal cognition, while the others were unable to do it. 96 teachers took part in a structured interview according to an intentionally prepared questionnaire which aimed to analyze their strategies of interpersonal cognition (IC). The investigators have identified three groups of teachers. The first group contained 28 teachers who used all cognitive strategies which were based on the principles of interpersonal cognition. The second group consisted of 27 teachers, who used less than half of such strategies. 41 teachers formed the third group. They used at least a half of the principles. (This group didn't take part in further investigations.)

Then the teachers of the first and second groups were asked to estimate comprehensively and to forecast the development of personality traits of the students they taught. Total 56 descriptions were received. An amount of analyzed traits was calculated in each description. The analysis revealed two groups of traits used by teachers to estimate their students. The first group contained formal characteristics of the students: age, appearance, their families' welfare standards and school progress. The second one included personality traits: interests, hobby, attitudes towards peers and grown-ups, some specific features of cognitive and emotional spheres, volitional control aspects and self-esteem. These personality traits were divided into groups (categories) characterizing spheres 
of psyche (see above the principle of orientation to an entire coverage of human personality traits).

The analysis of the descriptions has shown that the teachers of both groups used all the categories mentioned above. At the same time, the teachers of the first group used categories describing psychic traits of their students more often and the characteristics given by them were more substantial, adequate and informative. The characteristics given by the teachers forming the second group were superficial and formal.

Teachers belonging to different groups have made the following descriptions of one and the same student. The object was student A., 13 years old. The first description of the personality traits of the student was provided by a teacher of the first group (having 7 years' experience), the second description was made by a teacher of the second group (having 10 years' experience).

First description of A. A. is an $8^{\text {th }}$ grade student. His behavior generally depends on his emotions. They play a very important role in his life and the majority of his behavioral reactions can be called emotional. But in conflict situations he seeks cooperation, but often adapts and sacrifices his own interests and needs to satisfy the requirements of interlocutor. His self-esteem is overrated. He believes himself to be a merry, healthy, goodnatured and rather generous fellow.

A. is talkative and he likes reasoning, but it does not mean that he is always ready to go in the right direction. His actions are not likely to go too far. He is irresolute and light-minded. He usually tries to attract others' attention to himself. His desire to exhibit himself is evident. At the same time he does not notice that people around him do not approve such behavior. They don't often take it seriously. He is satisfied with its actions and behavior and is of a good opinion about them, which is another evidence of his exaggerated self-appraisal.

He does not have any learning motivation. Prestigious things are attractive to him; this might derive from his parents. The kid goes to school reluctantly, he does not like to do his homework and tries to finish the unfavourite task as soon as possible. Cognitive motivation is practically absent, he has an average intelligence. He pays attention only on what is identified as prestigious. The student is not professionally oriented, knows little about professions. The kid asserts that his parents haven't discussed his future occupation and education after the end of the $8^{\text {th }}$ grade. The A.s family con- 
sists of four members: a father, a mother and a younger brother. His contacts with the parents may be distorted, because even when A. states that his family is united and happy, there are some opposite signs.

Prospects of development. Care and approval of the parents is what is needed in this stage. They do not pay much attention to him recently due to the newly-born younger brother, which would lead to a conflict with his parents and further result in an attempt of escape or breaking his relations with the family. Lack of professional orientation and an attempt to achieve a prestigious position may be the reason why the teenager will study and work without taking into account his interests and skills, which is often followed by emotional dissatisfaction and self-discontent.

Second description of A. A is 13 years old. The boy is poor at studying, lazy, untidy, misbehaves at classes, rude, likes have his own way which results in frequent quarrels with everyone, he is quarrelsome by nature.

Prospects of development. If A. retains such attitudes to his study and behavior, the kid will not be able to complete his secondary education.

Main results of the psychodiagnostic testing of A. A.'s self - esteem is overrated. Intelligence level is normal. The control of emotional and impulsive reactions is weak. In conflict situations he tends to choose a strategy of adaptation. His has considerable verbal activity and is inclined to defensive verbal aggression. It is his demonstrative behavior and attempts to attract attention that is typical of him. Cognitive and learning motivation is absent. $\mathrm{He}$ is interested in football. He envies his junior brother, who, as he considers, is the centre of his family' attention and care. He is jealous of his parents and feels worthless.

To study differences between the teachers of both groups in terms of adequate estimation of personality traits of teenagers, a statistical nonparametric criterion $\chi^{2}$ was applied. The estimates that coincided with the psychodiagnostic results were regarded as adequate. The analysis of the data obtained has manifested that there are statistically significant differences between the two groups of teachers. It was ascertained that the teachers of the first group estimate motivation, cognitive abilities, self-esteem and emotional sphere significantly better $(p \leq .01)$. Statistically significant differences between the two groups of teachers have not been found, when estimation of interests, erudition, will and interpersonal relations was compared. 
While analyzing the results obtained, attention should be paid to the qualitative assessment of will and interpersonal relations given by the teachers. Even if the volitional sphere of a school kid was taken into consideration, all teachers of the third group used a single "lazy - not lazy" trait dichotomy. The estimates of the teachers from the first group were more substantial. They described the volitional sphere of the students on the basis of a combination of volitional properties: lazy, did not like working, lacking in initiative, spineless, could not stand up for himself / herself. The same can be applied to how the sphere of interpersonal relations was estimated. Basically, the teachers of the second group paid attention to such traits of the students as "quarrelsome - frictionless." In addition to the above-mentioned characteristic, the teachers of the first group described such communication traits as presence - absence of leadership, uninhibited - shy, trustful - suspicious, sociable - unsociable, etc.

Generally speaking, the results of this research show that the teachers of the first group, who used the strategies based on the principles of interpersonal cognition, adequately estimated the majority of the traits that their students displayed in the process of education and that characterized their motivation sphere, erudition, self-esteem, will, emotions and intelligence. However, the foregoing was not true for the teachers that were unable to use these strategies. They could give an adequate estimation of the traits which require no profound analysis of personality traits of the students: interests, erudition, proneness to conflict, laziness or lack of laziness.

A.V. Razumova, Psychology Department, Moscow State University, demonstrated in her further research dealing with specific aspects of interpersonal cognition that parents tended to view their children in a far more adequate manner, if they used four of six strategies based on the principles of interpersonal perception $(p \leq .05)$ (Razumova, 2004). Thus, the results, obtained from this sample of parents generally coincide with the data derived from the study of teachers. These results enabled to conclude that the cognitive strategies or methods based on the principles of interpersonal cognition, which were defined on the grounds of our theoretical analysis, appear to be conductive to better understanding of personality traits and behavior of children.

To ensure more efficient mastering of the aforementioned principles, a procedure called The Development of the Strategies of Interpersonal Cog- 
nition has been developed (Rozhdestvenskaya, 2004). It rests upon the theory of problem learning (A.V. Brushlinsky, A.M. Matyushkin), the theory of stage-by-stage development of knowledge and mental actions (P.Ya. Galperin, N.F. Talyzina) and the method of reflection development (I.I. Ilyasov, I.L. Mozharovsky). When applied to teachers, the technique has revealed that it is capable of determining and eliminating both misconceptions relative to people and inefficient methods of cognition.

According to this method, in the beginning of the motivation step students are explained how important the work to be done is. Afterwards they receive problem tasks. In our experiment, efficient assimilation of standard knowledge was determined by the following conditions:

1. Anonymous people having some outstanding abilities are taken as objects of the research (respondents are not informed of abilities and names of such people).

2. Abstracts from biographies comprising unimportant or everyday events are read out.

3. A respondent turns solely to his / her own experience, knowledge and skills during the first step of portraying the characters (or judging their deeds) under investigation.

4. Strictly after this task has been completed, the respondents are told names of the people they analyzed. As a rule, their descriptions contain mistakes. It is the realization of the mistakes they have made in determining the characters that stimulates the respondents to acquire methods helping to avoid such mistakes.

5. They are given such methods as the principles of interpersonal cognition. Assimilation of the principles is supervised by a moderator who makes the respondents reanalyze the deeds of the same people. Alongside with learning the principles of interpersonal cognition the students realize certain causes of their mistakes. (It is necessary to select as many biographical abstracts as it is sufficient to apply all six strategies of interpersonal cognition.) This step ends with a discussion of the work, when emphasis is put on use of scientific methods for cognition of a person.

6. Finally the above-described procedure is repeated, and the respondents analyze personality features of other people by means of the assimilated knowledge.

As it can be seen from the foregoing, the experiment is divided into several steps as required by active knowledge acquisition theory. The first 
to fourth conditions occur in the motivation step. The fifth condition relates to the step of understanding the diagram of orientation basis of actions. The sixth condition relates to the step of knowledge and skills practice.

This procedure was practically tested on teachers and teenagers (Rozhdestvenskaya, 2004). The method was further substantiated by a dissertation paper of I.V. Melnikova (Melnikova, 2007). 213 respondents took part in the research: 89 students of Moscow liberal arts institute for teachers' training, 32 graduating students of teachers' training college No. 9 of Moscow and 92 kids. The sample consisted of preschoolers and children from Moscow schools of general education and special schools. The students got acquainted and worked with the schoolchildren during their teaching practice.

The students were divided into four groups. In the first experimental group (Gr. 1) consisting of 29 students knowledge about the estimation strategies based on the interpersonal cognition principles was shaped at a training held by I.V. Melnikova, when The Development of the Strategies of Interpersonal Cognition method was used. A distinction of this training was use of a stressful event reconstruction technique suggested by I.V. Melnikova. ${ }^{3}$ The respondents of the second group (Gr. 2) were read a lecture on the procedure described above. This group comprised 32 respondents. The respondents of the third group (Gr. 3) were experimentally taught like in group 1, the only difference was that the stressful

3 This technique is used in the end of the stage of knowledge assimilation, when the atmosphere of confidence has been established in the group and the participants have got acquainted with all the principles of interpersonal cognition. Then the students are invited to recollect some past event when a teacher or an educator didn't understand him / her and hurt his / her feelings. Then a training participant is selected on a voluntary basis and his / her situation is dramatized. Further on, the participant is suggested to express his / her own feelings from the standpoint of a grown-up person and to explain to his / her former teacher why the latter was wrong. After that the group takes part in sharing their emotions. Finally, the moderator asks the participant to explain which scientific cognition methods the teacher should have used not to hurt the child. Then each participant may express his / her negative emotions associated with his / her own negative experience. The participants in turn tell their "offenders" about the emotions they have come through and explain how to get to know children so that not to hurt their psyche. In this case an "empty chair" technique is employed. The training participants have the right to refuse to do this task. Moreover, a "replay" technique may be suggested, when a participant may play again his / her situation as he / she likes. 
event reconstruction technique was not applied. This group consisted of 22 students. The fourth group (Gr. 4) was a control one and included 38 students. A traditional lecture was used in this case. It means the students got ready-to-use knowledge without practicing it.

Prior to and after the experimental teaching the respondents estimated the children whom they were observing during two practical teaching courses (which took place at the beginning and at the end of the academic year). The obtained characteristics were subjected to a comparison with the results of the children's psychological testing, and the data were processed by means of the statistical non-parametric criterion $\chi^{2}$.

Characteristics of the experimental groups.

Table 1

Specific features of teaching in the experimental groups, in which the procedure The Development of the Strategies of Interpersonal Cognition was used

\begin{tabular}{|c|c|}
\hline Groups & $\begin{array}{l}\text { Specific features of teaching in the experimental groups, } \\
\text { in which the procedure The Development of the Strategies } \\
\text { of Interpersonal Cognition was used }\end{array}$ \\
\hline Gr. 1.29 respondents & $\begin{array}{l}\text { A training form using the stressful event reconstruction } \\
\text { technique }\end{array}$ \\
\hline Gr. 2. 32 respondents & $\begin{array}{l}\text { A lecture form without using the stressful event reconst- } \\
\text { ruction technique }\end{array}$ \\
\hline Gr. 3.22 respondents & $\begin{array}{l}\text { A training form without using the stressful event reconst- } \\
\text { ruction technique }\end{array}$ \\
\hline
\end{tabular}

\section{Results}

It has been found prior to the experimental teaching that students of the experimental groups and the control group do not differ statistically in terms of their skills in handling the principles of interpersonal cognition.

The forming experiment has demonstrated that a level of proficiency in all six strategies of interpersonal cognition of the respondents of the $1^{\text {st }}$ group increased considerably $(p \leq .001)$. The estimation quality of all major personality traits of the children (motivation and value sphere, intelligence, erudition, emotional sphere, voluntariness and volitional properties, aptitudes $(p \leq .001)$ and character $(p \leq .01))$ became statistically better.

A level of proficiency in four strategies of interpersonal cognition has increased significantly in the respondents of the second group 
after the forming experiment: many participants started to use more adequate and essential criteria for estimating personality traits of the children, to view them in their development $(p \leq .001)$, besides, they tended to adhere to a probabilistic approach to estimation and to involve more traits to do that $(p \leq .01)$. It has also been found that after the forming experiment the participants of this group learned how to better estimate the children to the following parameters: voluntariness, emotional sphere, aptitudes $(p \leq .001)$, and character $(p \leq .01)$. Simultaneously, the differences between the estimates of children's motivation and values, intelligence and erudition turned out not to be statistically significant.

These results can be interpreted in the following way. Insignificant differences between the estimates of children's intellect can be explained by the fact that $75 \%$ students have already paid attention to this characteristic prior to the forming experiment. Yet it seems more difficult to explain the insignificant differences between the estimates of such parameters as "motivation and values" and "erudition." Before the forming experiment, mere $25 \%$ and $37 \%$ respondents, accordingly, took into consideration these parameters, and there were hardly any improvements in the results after the experiment. It has to be acknowledged that this may be due to some unknown factors that had an adverse effect on the experiment. The same arguments may be useful to explain why the forming experiment affected so slightly students' ability to analyze external and internal conditions having an influence on the children and to verify their conclusions in terms of practical activities typical of the children.

The forming experiment has positively affected the third experimental group, since the students applied five strategies of interpersonal cognition: using adequate and essential criteria for estimating children's personality traits; estimating a personality according to an analysis of both internal and external factors influencing the children; considering personality traits of the children in progress; using a probabilistic approach to the children; estimating the personality traits comprehensively $(p \leq .001)$. It has also been found that after the forming experiment the participants of this group learned how to better estimate the children on the subject to the following parameters: voluntariness, emotional sphere, aptitudes $(p \leq .001)$, and character $(p \leq .01)$. At the same time, the differences between the estimates given according to the "in- 
telligence" parameter seem to be insignificant due to the same reasons as mentioned before with respect to the second group. The differences are not significant in terms of the ability to verify judgements about the children within certain practical activities typical of the children.

As far as the control group is concerned, no statistically significant differences have been discovered, although certain positive changes of all the parameters in question have been visible.

It is worth mentioning that, in spite of the fact that the statistically significant positive results were obtained in all three groups, the respondents of the first group excelled the students of the second and third groups in terms of proficiency in all cognition strategies $(p \leq .001)$ and quality of estimation of children's personality traits. At the same time, the differences between the results of teaching in the second and third groups are insignificant. It allows to conclude that the methods of teaching used in the first experimental group turned out to be the most efficient, while the lack of differences in the results of teaching in the second and third groups was the evidence that, all other conditions being equal, the training form of teaching failed to overcome the lecture form.

\section{Discussion}

The results discussed above show that The Development of the Strategies of Interpersonal Cognition procedure is an efficient means of improving the interpersonal cognition for future teachers. The method can be used both in the lecture and training forms. The method proves to be most efficient when the training form of teaching and the stressful event reconstruction technique are applied. In this event, knowledge assimilation is considerably affected by emotions of the training participants. In this connection it should be pointed out that while the aforementioned procedure can readily be introduced into training of future teachers, specific aspects of higher school education impose restrictions on implementation of some training exercises.

It is known that one should be extremely careful about emotionally stressful exercises, because they may touch traumatic experience of students. The stressful event reconstruction technique is one of them; we turned to this technique solely for the purpose of study. Before the beginning of the first training, all participants of the research group gave 
their voluntary consent to subjecting their personal experience to further analysis. More to the point, the students were tested by means of sociometry and the scale of subdepression (Prokhorov, 2004, pp. 138-140). We have determined that there were no students in the group who were emotionally rejected, and that no participant was subdepressed or depressed. Besides, the researcher, who conducted the experiment, was an experienced teacher qualified as an educational psychologist and certified as a family counselor.

These restrictions made us pay more attention to emotional capability of the lecture form of teaching. During the research the participants described many cases, when their former teachers estimated them inadequately and mistreated them thus causing psychic traumas. We supposed that such situations were suitable as problem tasks in the motivation step of forming strategies of interpersonal cognition. Some preliminary results show that they seem to be more attractive to students than biographical facts about outstanding and well known people which were used in our research.

Moreover, we suppose that the efficiency of learning the strategies of interpersonal cognition will increase, if special video materials representing various situations of teachers traumatically affecting their students are involved.

Finally, the results of the studies analyzed in this article permit to draw the following conclusions. Cognitive techniques based on the interpersonal cognition principles are efficient strategies for providing better understanding of people. We have demonstrated that completeness and adequacy of estimating personality traits of children by teachers is determined by how well they managed to learn these strategies. Future teachers can be efficiently taught these strategies through The Development of the Strategies of Interpersonal Cognition method.

\section{References}

Berezina, A.V. (2003). Osobennosti formirovaniâ mežličnostnogo vospriâtiâ kak uslovie soveršenstvovaniâ obŝseniâ u podrostkov [The Peculiarities of Interpersonal Perception Development as a Condition of Adolescents' Interactions Improvement] (Candidate of Sciences dissertation). Moscow.

Grachikova, E.V. (2002). Kognitivnyj komponent mežličnostnogo vospriâtiâ kak professional'no važnoe kačestvo učitelâ [The Cognitive Component of Interpersonal 
Perception as a Teachers' Professional Trait] (Candidate of Sciences dissertation). Moscow.

Melnikova, I.V. (2007). Usloviâ formirovaniâ naučno obosnovannyh sposobov ocenki ličnostnyh svojstv detej $u$ budusih pedagogov [The Conditions of Teaching Scientifically Grounded Strategies of Estimating Children Traits in Future Teachers] (Candidate of Sciences dissertation). Moscow.

Pisarenko, V.M. (1986). Rol' psihiki v obespečenii èmocional'noj ustojčivosti [The Role of Psyche in the Development of Emotional Stability]. Psihologičeskij žurnal, 1, 62-72.

Pisarenko, V.M., \& Rozhdestvenskaya, N.A. (1998). Metody soveršenstvovaniâ mežličnostnogo poznaniâ [The Methods of Interpersonal Cognition Improvement]. Vestnik Moskovskogo universiteta. Seriâ 14 "Psihologiâ," 2, 74-80.

Prokhorov, O.A. (Ed.). (2004). Praktikum po psihologii sostoânij [Practical Training on the Psychology of States]. Saint Petersburg: Reč'.

Razumova, A.V. (2004). Adekvatnost' obraza rebënka u roditelej s raznymi stilâmi semejnogo vospitaniâ $i$ ličnostnymi osobennostâmi [The Adequacy of a Child Image in Parents having Different Family Styles and Personality Traits] (Candidate of Sciences dissertation). Moscow.

Rozhdestvenskaya, N.A. (2004). Sposoby mežličnostnogo poznaniâ: psihologopedagogičeskij aspekt [The Strategies of Interpersonal Cognition: From the Aspect of Educational Psychology]. Moscow: PER SÈ.

Talyzina, N.F. (1981). The Psychology of Learning. Moscow: Progress. 